\title{
Is Glyphosate a Key Factor in Mesoamerican Nephropathy?
}

\section{Stephanie Seneff' ${ }^{*}$ and Laura F Orlando ${ }^{2}$}

${ }^{1}$ Computer Science and Artificial Intelligence Laboratory, MIT, Cambridge MA 02139, USA

${ }^{2}$ Environmental Health, Boston University School of Public Health, Boston, MA 02118, USA

\begin{abstract}
Mesoamerican nephropathy (MeN), also known as chronic kidney disease of unknown etiology (CKDu), is an unusual form of kidney disease not associated with diabetes, hypertension, or glomerular nephritis. It has a number of known risk factors, none of which adequately explain the skyrocketing prevalence of the disease among sugarcane workers in El Salvador and Nicaragua. In this paper, we narrow the research focus from agricultural chemicals, in general, to glyphosate, in particular, an herbicide routinely used on sugarcane. We explain how glyphosate compellingly contributes to CKDu, by reviewing the evidence for glyphosate's direct toxicity to kidneys and showing how the herbicide amplifies the damage to kidneys from other known risk factors. Using standard web search on index words and phrases, we gathered and perused a large collection of papers describing the pathology of MeN and associated metrics, on the one hand, and the mechanisms of toxicity of glyphosate in humans, animals and in in vitro studies, on the other hand. We show that glyphosate is used on sugarcane in three distinct ways, with exposure greatest when the herbicide is used as a ripener near harvest time. We identify several pathologies associated with MeN that have been found to be implicated in papers on glyphosate exposure, such as enhancing the growth of Clostridia species and fungus, promoting arsenic toxicity, suppressing the synthesis of adrenocorticotropic hormone (ACTH), disrupting fructose metabolism, and promoting dehydration and high serum urate. A companion paper explains how glyphosate's substitution for glycine could cause additional renal damage. Together, these two papers strongly suggest that glyphosate is a causative agent in CKDu. Overall, the research literature provides compelling evidence that glyphosate exposure is a significant factor in MeN. Glyphosate usage on crops should be curtailed in order to protect the agricultural worker population from this devastating and life-threatening disease.
\end{abstract}

Keywords: Chronic Kidney Disease of unknown etiology (CKDu); Mesoamerican Nephropathy (MeN); Glyphosate; Sugarcane; Nicaragua; El Salvador

\section{Introduction}

Mesoamerican nephropathy (MeN), also known as chronic kidney disease of unknown etiology $(\mathrm{CKDu})$, is an unusual form of kidney disease specifically not associated with diabetes, hypertension, or glomerular nephritis. The unique symptomatic profile of $\mathrm{MeN}$ includes asymptomatic reduction in glomerular filtration rate, hyperuricemia, hypokalemia, tubulointerstitial disease with secondary glomerulosclerosis and glomerular ischemia. Unlike most types of kidney disease, blood pressure is not elevated, and, in fact, hypotension could be considered a feature of the disease. Hyperosmolarity due to extreme dehydration activates the vasopressin and aldose reductasefrutockinase pathways that can lead to renal injury [1]. MeN's prevalence has exploded among young male agricultural workers in Nicaragua and El Salvador in the past decade, with sugarcane workers being the most acutely affected. Figure 1 shows CKD mortality rates in various countries in North America, revealing the striking anomaly for males in Nicaragua and El Salvador. Figure 2 shows mortality as a function of age, again showing that men 25-59 years old from El Salvador and Nicaragua are especially susceptible to CKD mortality, compared to women and to other countries in North America.

Between 2005 and 2012, there was a 50\% increase in hospitalizations for CKD in El Salvador, making it the leading cause of death in adults in the country's hospitals [2,3]. The disease is more prevalent in the Pacific lowlands of these countries compared to communities at higher elevations ( $18 \%$ vs $1 \%)$ [4]. While sugarcane workers are the most affected among the agricultural communities, a study by Peraza et al. found that those sugarcane workers who work along the Pacific coast were ten times more likely to have elevated serum creatinine (a marker for kidney disease) than highland workers $(\mathrm{p}<0.001)$ [5]. The unique symptom profile of CKDu challenges the mind to explain the underlying etiology. It seems likely that intense physical labor in tropical heat might lead to dehydration that stresses the kidneys. It has also been suggested that nonsteroidal anti-inflammatory drugs (NSAIDs), used to ease pain, might work synergistically with dehydration to compromise kidney function. Other contributing factors may include exposure to pesticides and toxic metals, such as arsenic, cadmium, aluminum, iron, and lead $[6,7]$. Mycotoxins such as ochratoxin and aflatoxin have also been linked to the disease [8]. But these factors seem inadequate to account for the extreme devastation of the disease process.

A study by VanDervort et al. published in 2014 specifically addressed the question of whether high temperature or agricultural chemicals were the most significant factors in CKDu. They wrote: "High temperatures do not appear to strongly influence occurrence of unCKDu proxies. $\mathrm{CKDu}$ in El Salvador may arise from proximity to agriculture to which agrochemicals are applied, especially in sugarcane cultivation" [9]. A paper by Clark et al. published in 2016 proposed that the CKD associated with sugarcane agriculture in Nicaragua is likely due to a combination of glyphosate toxicity and dehydration due to heavy labor in extreme heat [10].

A 2014 study on farming communities in El Salvador found that $96 \%$ of the study subjects had contact with agrochemicals [11]. $89 \%$

*Corresponding author: Stephanie Seneff, Computer Science and Artificial Intelligence Laboratory, MIT, Cambridge MA 02139, USA, Tel: +16172531000; E-mail: seneff@csail.mit.edu

Received December 29, 2017; Accepted January 09, 2018; Published January 14,2018

Citation: Seneff S, Orlando LF (2018) Is Glyphosate a Key Factor in Mesoamerican Nephropathy? J Environ Anal Toxicol 7: 542. doi: 10.4172/2161-0525.1000542

Copyright: (๑) 2017 Seneff S, et al. This is an open-access article distributed under the terms of the Creative Commons Attribution License, which permits unrestricted use, distribution, and reproduction in any medium, provided the original author and source are credited. 


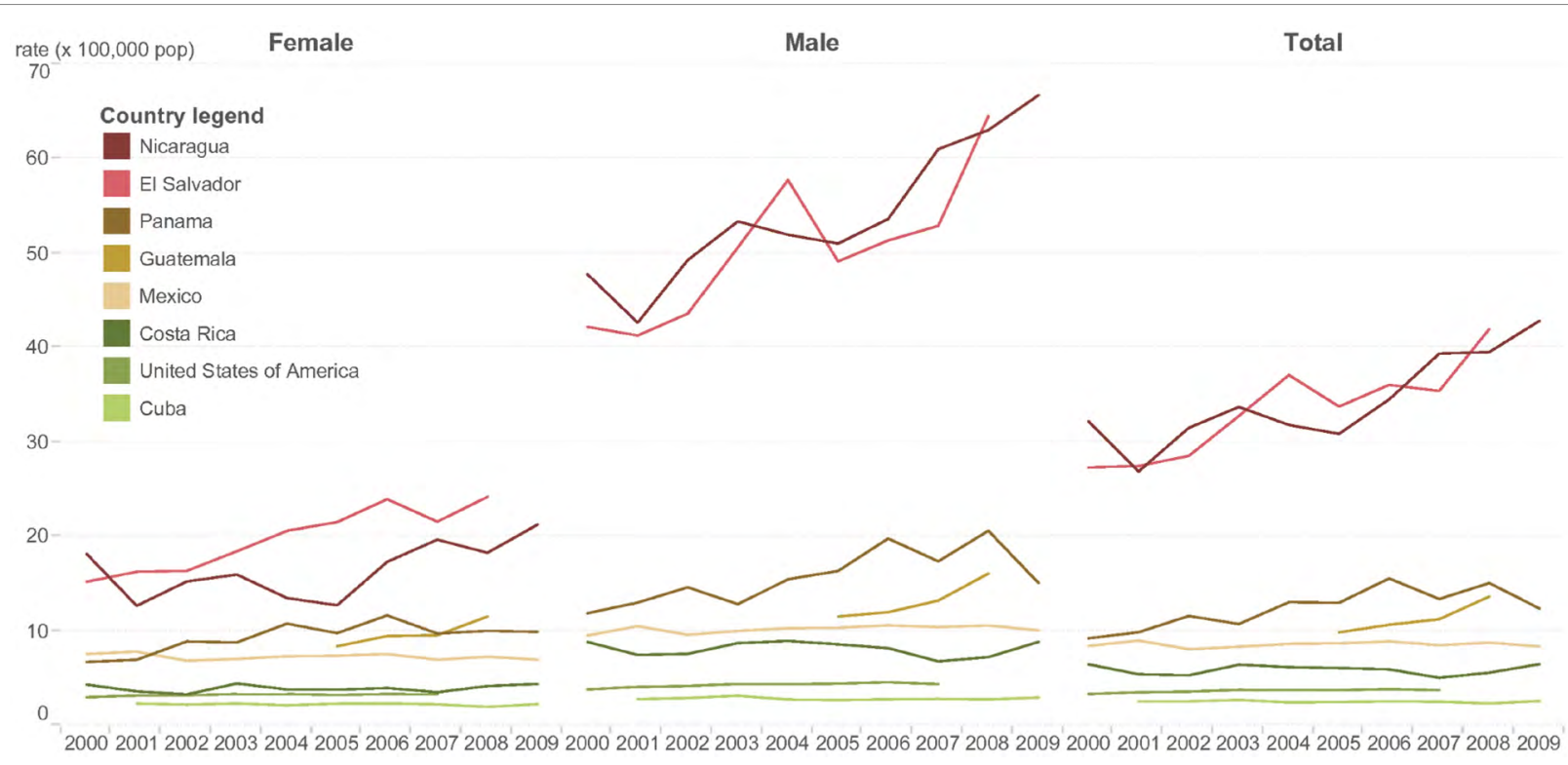

Figure 1: Chronic kidney disease (N18; International Classification of Diseases, tenth revision [ICD-10]) age-standardized mortality rate, selected countries, 20002009. Reproduced from Ordunez et al. [2].

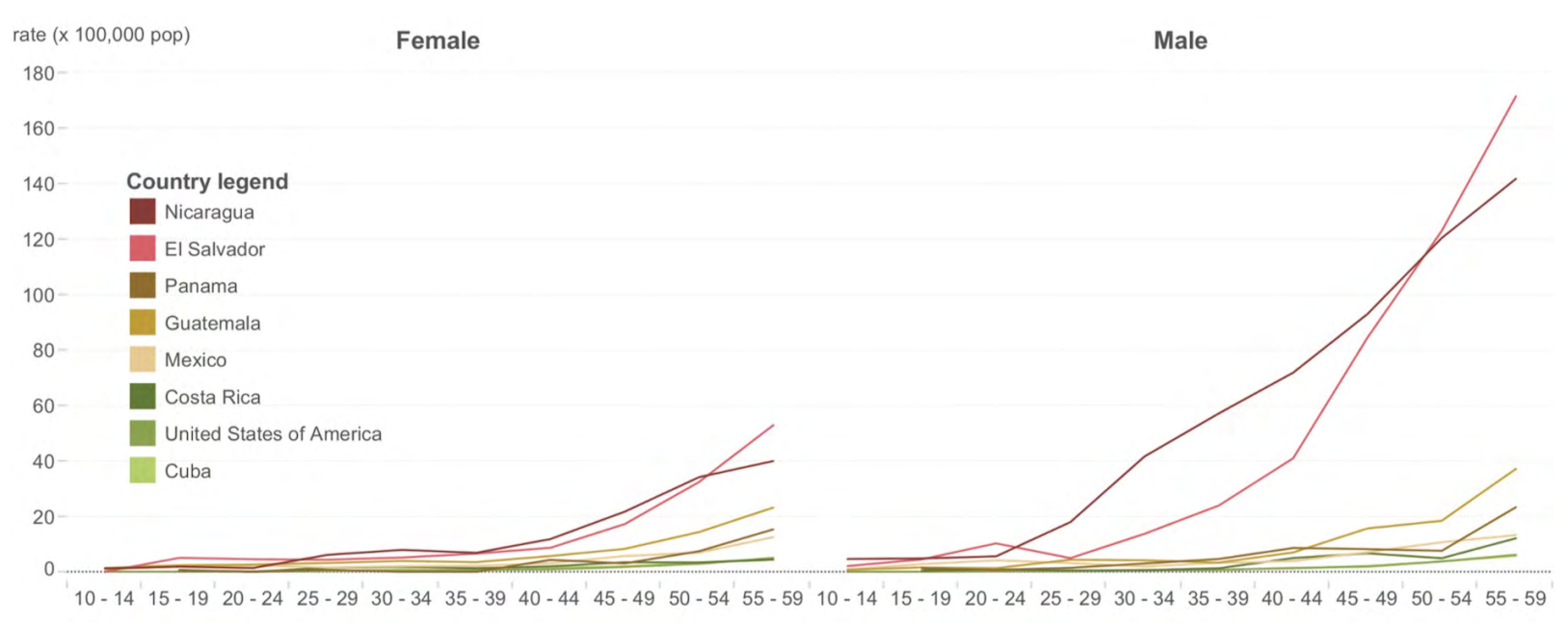

Figure 2: Chronic kidney disease (N18, ICD-10) age-specific mortality rate, selected countries, around 2008. Reproduced from Ordunez et al. [2].

of the study participants were farmers, and $76 \%$ experienced profuse sweating. Diabetes was present in only $4 \%$ of the patients. They proposed that "nephrotoxic environmental agents" play a key role in the disease process. In fact, another paper from the same issue was aptly titled, "Chronic Kidney Disease of Unknown Etiology Should Be Renamed Chronic Agrochemical Nephropathy" to draw more attention to this aspect of the disease process [12].

Glyphosate is the most common chemical used to induce the maturation or ripening of cane in order to increase the sugar content at harvest time $[13,14]$. It is also used to kill weeds and is the most widely used herbicide for the eradication of cane stools in preparation for new planting [15]. Glyphosate is not the only herbicide used on cane, but its fingerprints on CKDu demand a special focus. A series of papers by Jayasumana et al. linked glyphosate exposure to a nephrotic disease among rice growers in Sri Lanka that is similar to MeN $[6,16,17]$.
Urinary excretion of heavy metals and glyphosate were found to be markedly elevated in people living in areas where Sri Lankan agricultural nephropathy was endemic. It is significant that MeN first appeared in the mid 1990's, just as agricultural usage of glyphosate was ramping up. During the period when hospitalizations for CKD in El Salvador increased by $50 \%$, the global use of glyphosate for agricultural purposes nearly doubled, increasing from 388,729 metric tons to 716,676 metric tons [18]. Over the last decade, 6,078,138 metric tons of glyphosate have been applied [18]. In 2008, the Monsanto Company, whose Roundup herbicides are the largest global brand, signaled its interest in increasing cane's tolerance to glyphosate with the purchase of the world's largest sugarcane breeding company, CanaVialis.

\section{Dietary Factors}

A significant marker of $\mathrm{MeN}$ is hyperuricaemia, and diet plays an 
important role in influencing urate synthesis by the liver. In particular, both alcohol and fructose are known to increase hepatic urate synthesis, and breakdown of purine-rich foods yields urate as a by-product [19]. Urate can be toxic to the kidney when it precipitates out, forming crystals. It is clear that agricultural workers along the coast in Mesoamerica have an increased risk to MeN compared to those working more inland and at higher elevations [5]. While this difference has been attributed to the higher temperature at sea level, another likely synergistic contributor could be increased access to dietary seafood in a coastal region. Seafood has high levels of purines, which, through their breakdown, can contribute to high urate levels. Seafood is also a good source of heme iron, and iron overload, particularly in the context of glyphosate, can damage the kidneys. Finally, seafood can be contaminated with toxic metals, especially arsenic [20]. A US-based study on a National Health Nutrition and Examination Survey (NHANES) population from 2003 to 2006 found higher levels of urinary arsenic, in both organic and nonorganic forms, for those who consumed seafood on a regular basis [21].

"Lija" is a homemade alcoholic drink that is popular in Nicaragua. Consumption of lija is associated with a more than 2 -fold increased risk to MeN [22]. Lija is sometimes stored in industrial metal containers that previously held pesticides. It has also been suggested that heavy metals such as lead may have leached into the beverage from processing and storage containers. Glyphosate was first patented as a chelating agent [23]. As such, it would be effective in leaching metals such as aluminum and lead from containers. Fructose from sweetened beverages, popular among day laborers in Central America for quenching thirst, is another likely contributor to elevated urate [24-27]. A human study on obese subjects showed a remarkable differential between glucose and fructose in terms of their effects on serum urate [24]. Consumption of fructose as $25 \%$ of energy requirements for just 10 weeks, compared to glucose, induces a highly significant increase in circulating uric acid $(\mathrm{p}<0.0001)$. The mechanism by which fructose effected this increase is thought to be due to depletion of ATP and inorganic phosphate, due to increases in fructose-1-phosphate and glyceraldehyde-3-phosphate synthesis from fructose. This leads to increased nucleotide degradation into uric acid [28]. Fructose may also lead to upregulation of de novo synthesis of purines from glycine [29].

A study comparing fructose-fed Sprague-Dawley rats with dextrose-fed rats revealed that fructose had a direct toxic effect on the kidneys [30]. Fructose-fed rats had greater protein excretion, higher serum creatinine, more renal hypertrophy, and higher mortality. Histologically their kidneys showed more glomerulosclerosis, tubular dilation, tubular atrophy, interstitial inflammation and interstitial collagen accumulation. The renal tissue showed higher levels of the inflammatory cytokine monocyte chemoattractant protein-1 (MCP-1). Dehydration activated the aldose reductase pathway in mouse kidney, leading to an increase in renal sorbitol and fructose levels [31]. This was associated with renal injury, indicated by an increase in serum creatinine and renal MCP-1, proximal tubular cellular injury, and renal fibrosis. It was proposed that this could be a model for $\mathrm{MeN}$, and that high-fructose drinks could exacerbate the damaging effects of endogenously generated fructose in human kidneys.

\section{Smoke Exposure from Burning Cane}

The most at-risk group for MeN appears to be sugarcane workers, and increased symptom manifestation is linked to the harvest season, when strenuous labor is involved with cutting the sugar cane stalks with a machete and workers are exposed to smoke from burning cane [3236]. Similar to other cane-growing countries, cane fields in Nicaragua and El Salvador are burned as close to harvest time as possible to reduce leafy material and facilitate transportation and processing. The burning of the sugarcane stalks previously exposed to glyphosate at harvest time is likely a source of toxic glyphosate-containing fumes, further contributing to exposure risk. A study from 2014 showed that burnt sugarcane harvesting caused an increase in serum creatinine

\section{Age Adjusted End Stage Renal Disease Deaths (ICD N18.0 \& 585.6)}

plotted against \%GE corn \& soy planted $(R=0.9578, p<=4.165 \mathrm{e}-06)$

and glyphosate applied to corn \& soy $(R=0.9746, p<=7.244 \mathrm{e}-09)$

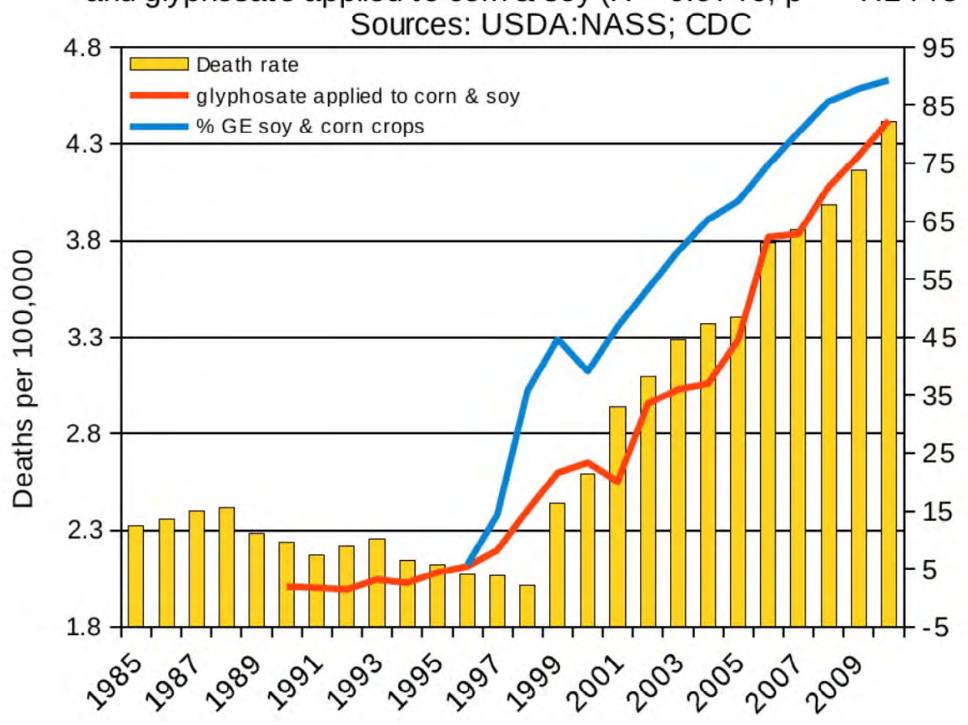

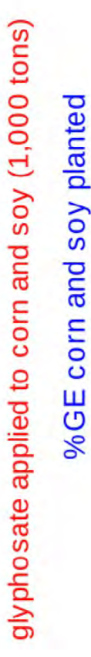

Figure 3: Correlation between age-adjusted End Stage Renal Disease deaths and glyphosate applications and percentage of US corn and soy crops that are genetically engineered. Reproduced from Swanson et al. [80]. 
and decrease in glomerular filtration rate, along with rhabdomyolysis, hypovolemia, systemic inflammation and oxidative stress [32]. A highly significant increase in micronucleus formation in oral epithelial cells and lymphocytes during the sugarcane harvest season $(\mathrm{p}<0-.001)$ suggests genotoxicity of chemicals released into the smoke [33]. Jiaqiang et al. show the ability of amino acid transporters to transfer glyphosate from the nose to the brain then directly into the central nervous system [37]. This bypass of the liver could delay metabolism of the molecule. Dermal exposure could do the same [38].

\section{Uremic Toxins}

One of the key factors in glyphosate toxicity is its ability to act as an antibiotic, preferentially killing beneficial species in the gut and encouraging pathogens to overgrow $[36,39,40]$. Clostridia species are especially resistant to glyphosate, and they produce multiple uremic toxins such as p-cresol sulfate and indoxyl sulfate [39]. In fact, chronic $\mathrm{CKD}$ is a strong risk factor for C. difficile infection [40]. p-Cresol metabolites accumulate during CKD, and there is a shift from sulfation to glucorindation upon progression, suggesting sulfate depletion [41-43]. Furthermore, proximal tubular epithelial cells transition to mesenchymal cells (EMT) upon exposure to p-cresol sulfate, leading to fibrosis. Several fungus communities, including Aspergillus, colonize sugarcane fields [44-46]. The Aspergillus species produce a large number of mycotoxins that are nephrotoxic, such as aflatoxin B1 (AFB1), ochratoxin A (OTA), and fumonisins [47-51]. Two examples of nephrotoxic mycotoxins will be discussed here: AFB1 and OTA. The United Nations' Food and Agricultural Organization estimates that $25 \%$ of all food is contaminated with mycotoxins [52]. Food and fields should be considered as exposure pathways since both AFB1 and OTA can permeate through the skin [53]. Takahashi et al. found Aspergillus flavus and Aspergillus parasiticus, which produce AFB1, in 53\% of cane field soils sampled and aflatoxin in $89 \%$ of sugarcane stems [52]. Thirtyone patients with CKDu in Sri Lanka showed aflatoxins in $61.29 \%$ and ochratoxins in $93.5 \%$ of urine samples [54]. In Tunisia, OTA was detected in the blood of the majority of people with CKDu [55].

Sugarcane can be harvested by machines or cut by hand. Though mechanical harvesting can be less expensive than manual labor on large plantations, cutting by hand with machetes remains common in Mesoamerica [56-58]. Cane cutters cut at the base of the stalk, where the most sucrose is located. This also is the main location of fungal growth [45]. It is not uncommon for cane workers to chew on raw cane, another possible exposure pathway for mycotoxins.

Several studies demonstrate that glyphosate impairs agricultural soil ecosystems [57-60]. Even though fungi, bacteria, and plants all have the shikimate pathway, glyphosate influences individual organisms in different ways [61]. For instance, aflatoxins adapt not only to the very high temperatures found on the Pacific coastal plains in Central America, where sugarcane is grown, but also to glyphosate [44]. Barberis et al. reported, "All strains of Aspergillus section Flavi assayed were tolerant to glyphosate." The use of glyphosate on sugarcane fields creates conditions favorable to Aspergillus and their toxic secondary metabolites by inhibiting the growth of mycorrhizal fungi and stimulating the growth of phytopathogenic fungi $[62,63]$. These fungi use glyphosate as a nutrient and an energetic substrate [58,64]. The use of glyphosate was associated with an uptick in cereal diseases from Fusarium pathogens in Canada [65].

Bennett and Klich in their comprehensive review of mycotoxins state that, "in the absence of appropriate investigative criteria and reliable laboratory tests, the mycotoxicoses will remain diagnostically daunting diseases [48]. Still, much is known about specific renal assaults by mycotoxins. OTA accumulates in the proximal tubule and causes oxidative stress and tubular damage $[50,66]$. It also inhibits ATP mitochondrial production [48]. Aflatoxins are carcinogenic, mutagenic, toxic to the liver and kidneys and immune suppressants, and they inhibit several metabolic systems $[48,67,68]$. AFB1 induces tubular damage and glomerular injury [69]. In animal studies, it also provokes oxidative stress in renal tissue [66,70,71]. Cytochrome P450 (CYP) enzymes help metabolize and clear most drugs and other xenobiotics. In the kidney, they reside predominately in the proximal tubules $[72,73]$. They are located there to deal with proximal tubular toxicants like NSAIDs and OTA. Glyphosate inhibits the CYPs [39]. The combination of the degradation of tubular integrity and the compromise of CYPs could boost the damage from a chemical insult, fungal toxicity, or physiological stress.

\section{Glyphosate and Hepatic/Renal Damage}

In this section, we review the research literature linking glyphosate to hepatic and renal damage, based on human epidemiological studies, animal-based studies, and in vitro studies. A cross-sectional interview study was conducted in 2011 in communities of the Bajo Lempa region of El Salvador, involving 42 males with confirmed MeN [2,3]. All of the subjects reported buying and managing pesticides, and $73.8 \%$ specifically reported occupational exposure to glyphosate. The mechanism by which glyphosate achieves an increase in sugar to starch ratio involves inhibition of phosphoenol pyruvate carboxylase (PEPC) [74]. Glyphosate's inhibition of EPSP synthase, which also has PEP as substrate, within the shikimate pathway, is believed to be the main mechanism of glyphosate toxicity to plants [75]. As PEP accumulates due to suppression of the enzymes that metabolize it, it suppresses its own synthesis from fructose, leading to an increase in sugar content in the crop.

It can be anticipated that a similar pathology would occur in the gut of a human consuming fructose, because gut microbes also use EPSP synthase in the shikimate pathway to produce aromatic amino acids with PEP as substrate. Excess fructose consumption is believed to be a significant factor in fatty liver disease, because the liver converts fructose to fatty acids in order to prevent it from reaching the general circulation [76]. Fructose is ten times as potent as a glycating agent as glucose, and therefore it is essential for the liver to clear it from the circulation. Metabolomic and proteomic analysis showed activation of biomarkers linked to non-alcoholic fatty liver disease and subsequent steatohepatitis in response to ultra-low doses of glyphosate-based herbicides [77]. Ultrasound examination indicated fatty liver disease in $93.5 \%$ of patients in El Salvador suffering from MeN [11]. Excess fructose exposure in the liver will also increase the hepatic production of urate. An epidemiological study by Swanson et al. examined correlations between the rise in incidence of a large number of debilitating diseases and glyphosate usage on core crops in the United States [78]. In particular, Figure 1 in this paper (reproduced here as Figure 3) shows a striking correlation between deaths due to end stage renal disease and glyphosate usage between 1997 and 2010. The correlation coefficient was 0.975 with a $p$-value of 7.24E-9.

A study based in China involved 80 cases of poisoning by glyphosate through intentional ingestion of Roundup [79]. Multiple organs were affected, but especially the gastrointestinal tract. Fourteen percent of the 80 cases experienced renal damage. A characteristic symptom preceding death (which occurred for 7 patients) was severe hypotension unresponsive to either intravenous fluids or antihypotensive agents 
(vasopressor drugs). As we argue in a companion paper, we believe that glyphosate can disrupt the function of aquaporin, which is normally upregulated in the renal tubules in response to vasopressin and protects from renal water loss through urine. In a study of 245 patients in a Korean population, $26 \%$ of patients exposed to toxic levels of glyphosate developed hypotension, and this was associated with elevated levels of creatinine as well as long QTc interval [80]. Hypokalemia, a key feature of $\mathrm{MeN}$, is one of the most important risk factors for QT prolongation [81]. Long QT syndrome is associated with kidney disease [82,83]. In a study of patients with chronic renal failure, $41 \%$ suffered from QT prolongation, and this was correlated with the number of years of kidney failure and with low serum potassium and calcium levels [82].

A study on rats involving a low-dose exposure to Roundup and/ or GM Roundup-Ready feed over the entire lifespan revealed damage to the liver and kidneys, increased risk to various tumors, and early death in the treatment groups [84]. The authors noted that $76 \%$ of the discriminant variables versus controls were kidney-related. A subchronic toxicity study on rats exposed to $375 \mathrm{mg} / \mathrm{kg}$ glyphosate for eight weeks showed damage to the stomach, pancreatic acinar cells, spleen, brain, liver and kidney [85]. Through histopathological examination of the kidneys, the authors noted glomerular degeneration, mononuclear cell infiltration into the interstices of the tubules, and tubular necrosis. Prior supplementation with zinc ameliorated these effects. Serum urea is an indicator of an excessive breakdown of proteins and/or insufficient clearance due to kidney disease. A linear relationship between serum urea levels and urinary glyphosate was found in a study on dairy cows exposed to high levels of glyphosate in their GMO feed [86]. A study comparing patients with CKD with controls revealed a highly significant doubling on average of the serum urea levels $(p<0.001)$ [87]. Glyphosate increases the production of reactive oxygen species, resulting in oxidative stress, especially in the liver, kidneys and testis $[77,88,89]$. Consistent with this, a comet assay study revealed DNA damage in subjects from Ecuador exposed to glyphosate, suggesting a genotoxic effect of glyphosate [90]. An in vivo transcriptome investigation involving female rats exposed to ultralow doses of Roundup (50 ng/L glyphosate equivalent) demonstrated an increased incidence of liver and kidney pathologies [91]. A chronic glyphosate-exposure study on 198 male mice carried out by Bio/ dynamics in 1983 and submitted to Monsanto found four cases of renal tubule adenomas, an extremely rare kidney tumor, among the exposed mice [92]. The probability of observing this rare tumor four times in 198 mice is $\mathrm{p}=0.0064$, when considering the historical controls of the same laboratory.

\section{Urate}

A paper from 2015 argued that MeN might be a uric acid disorder [31]. Male workers exposed to heat stress along with physical exertion are predisposed to recurrent water and volume depletion, often accompanied by urinary concentration and acidification. Uric acid is generated during heat stress, in part because of nucleotide release from damaged muscles. Crystal formation in the kidneys is then the source of renal damage. These authors confirmed that urate crystals were commonly found in the urine of sugarcane workers in El Salvador. Elevated serum uric acid was a consistent metric for $\mathrm{MeN}$ in a study based in El Salvador [34]. A recent study on patients with $\mathrm{MeN}$ in northwestern Nicaragua compared their disease metrics with those associated with members of the NHANES database suffering from CKD. Multivariable regression analysis revealed that serum uric acid levels were on average $2 \mathrm{mg} / \mathrm{dL}$ higher in patients with MeN compared with their NHANES counterparts [87].

Hyperuricemia is directly associated with progressive kidney failure [93-95]. Hyperuricemia is also an independent risk factor for later development of CKD [96-99]. Acute uric acid nephropathy occurs following renal tubular obstruction by uric acid crystals. As the $\mathrm{pH}$ becomes more acidic during the course of concentration of urine in the tubular system, the concentration of urate needed for precipitation of crystals goes down. In animal models of uric acid nephropathy, precipitation of uric acid crystals obstructs the tubules, collecting ducts, pelves and ureters. Crystal deposition increases tubular and intrarenal pressure, and compression of the renal venous network causes an increase in renal vascular resistance and a fall in renal blood flow. This can lead directly to a decline in glomerular filtration and a direct path to acute renal failure.

Elevated serum urate can contribute to renal damage even in the absence of crystal formation [100]. It has been shown that uric acid contributes to endothelial dysfunction in part by suppressing the synthesis of nitric oxide (NO), a signaling gas that relaxes smooth muscles, promoting vascular flow. Thus, uric acid can induce vascular constriction in the renal tubules, promoting a hypoxic state that induces an inflammatory response. This would work synergistically with tubular fibrosis to deplete oxygen supply to the tubular epithelial cells. Hyperuricemia in rats caused an increase in macrophage infiltration even in the absence of crystal formation [101]. Uric acid levels in humans are linked to preglomerular arterial disease [25]. Decrease in renal blood flow causes injury to the proximal tubules by depleting ATP, disruption of calcium homeostasis, and the generation of free radicals [102]. Damaged tubular cells are released into the tubular lumen causing obstruction.

\section{ACTH}

Adrenocorticotropic hormone (ACTH) is neuroprotective in chronic kidney disease, as well as in acute kidney disease [103-105]. Tumor necrosis factor $\alpha$ (TNF- $\alpha)$ is a key cytokine expressed in the inflammatory response. Injection of TNF- $\alpha$ into the kidney elicits massive cellular apoptosis in the tubules. The typical response pattern includes acute tubular necrosis, characterized by vacuolization of proximal tubular epithelium, epithelial necrosis, sloughing of tubular cells into the lumen, loss of the brush border, nuclear enlargement and prominent inflammatory infiltration. Remarkably, a dose of ACTH gel of $10 \mathrm{IU} / \mathrm{kg}$ greatly ameliorated these histological lesions [105].

Multiple studies have shown that Roundup suppresses the release of ACTH by the pituitary gland [106-108]. A study exposing rats to $10 \mathrm{mg} / \mathrm{kg}$ per day of Roundup for two weeks revealed reduced production of corticosterone by the adrenal glands, despite the fact that the ACTH receptors remained intact [106]. Exogenous treatment with ACTH rescued steroidogenesis in the exposed rats. They proposed that Roundup disrupts the hypothalamic-pituitary axis leading to reduced expression of ACTH by the pituitary gland. Cericato et al. have demonstrated that fish exposed to sublethal doses of glyphosate have an impaired capacity to raise cortisol levels in response to stress [107]. A later paper by the same authors showed that glyphosate's suppression of cortisol production in interrenal tissues in fish (corresponding to the adrenal glands in mammals) is caused by its disruption of the release of ACTH from the pituitary gland [108].

\section{Addressing the MeN Epidemic}

We have postulated that glyphosate is the cause of Mesoamerican nephropathy $(\mathrm{MeN})$, with the synergistic involvement of several cofactors having a role in its progression to end-stage renal failure. Perhaps with the mounting evidence of glyphosate's toxic effects, the 
elimination of the herbicide on sugarcane in Central America is not an unreasonable public health goal. In the meantime, is there something that can be done to halt the progressive deterioration of renal function in cane workers? MeN is an occupational disease [109]. So what would workplace intervention look like on a sugarcane plantation? It might include actions by management to: reduce agrochemical exposures; prevent dehydration and heat stress; recognize and treat rhabdomyolisis without the use of acetaminophen or NSAIDs; stop burning cane; record and publicly share data on the use of agricultural chemicals (what, when, where, how much); and acknowledge poverty as a social determinant of $\mathrm{MeN}$ by increasing wages and other worker support.

What else can be done? Climate change should be recognized as a co-factor in MeN [110-112]. The increase in temperatures in already hot places like the Pacific coastal plains in Central America impact $\mathrm{MeN}$ in at least two ways: more heat stress and dehydration. It should be noted that increasing ethanol production as a substitute for fossil fuels is problematic in the framework of $\mathrm{MeN}$ mitigation. Sugarcane is a common feedstock for ethanol production. For instance, in Brazil, the world's largest grower of sugarcane, the majority of harvested sugarcane is used to make ethanol $[113,114]$. The cost of increased cane production to meet global demand for ethanol is not only worker health but also the loss of land for small farmers, deforestation, and water pollution [115-117]. Unless the conditions for growing, managing, and harvesting sugarcane are changed to reflect our greater understanding of $\mathrm{MeN}$, increasing sugarcane acreage to boost ethanol sales will also likely increase deaths from chronic kidney disease among cane workers.

Numerous studies about supportive therapies for acute kidney injury and CKD are available, but Mesoamerican nephropathy has not been slowed or stopped [118-120]. For example, in El Salvador and Nicaragua, from 1990 to 2009, male death rates from kidney failure increased 458\% [121]. Very few patients in Central America with endstage renal failure receive dialysis or kidney transplants [122]. The complex physiological processes that are part of $\mathrm{MeN}$ and the lack of consensus about its cause help contribute to poor health outcomes $[87,123]$. Nevertheless, the specific site of injury to the kidney in people with $\mathrm{MeN}$ and the mechanisms of harm caused by glyphosate give important clues to how cane workers - without access to advanced medical care and with limited finances - might treat renal assaults.

Intestinal fibrosis and tubular injury are clinical features of MeN [87,124-127]. Novel therapies that help prevent intestinal fibrosis and protect the tubules include heparin; ACTH gel; oxygen free radical scavengers such as ginseng, curcumin, alpha-lipoic acid (ALA), Vitamin E, and propofol; and trace elements such as selenium and zinc $[70,105,128-131]$. It should be noted that the National Kidney Foundation advises against the use of all herbal supplements [132]. Research opportunities abound for the clarification of advice with regard to the use of supplements for the treatment of kidney injuries, and also to address the inflammation and oxidative stress commonly associated with $\mathrm{MeN}$.

Low-level light therapy (LLLT) may modulate chronic kidney disease progression [133]. LLLT seems especially promising because of its ease of use and low cost. It is also non-invasive and painless. In one animal study, LLLT had a protective effect on renal interstitial fibrosis [134]. Another study showed improved renal blood circulation in 58\% of patients along with increased diuresis, and improved filtration and concentration functions [135]. In Brazil, the Federal University of Health Sciences of Porto Alegre has an on-going clinical trial looking at LLLT treatment for chronic kidney disease [136].
As with all disease prevention and treatment, diet is of critical importance. Probably the three most important interventions with regard to diet and $\mathrm{MeN}$ would be the elimination of glyphosate and reduction of fructose from the diet, and securing chemical and pathogen-free water $[30,87,137-140]$. The consumption of alcohol has been identified as a possible co-factor in MeN [22]. What may be particularly significant is the kind of alcohol consumed. Sanoff et al. showed that homemade liquor (lija) consumption in Nicaragua was associated with increased odds of having renal injury [22]. Homemade liquor does not always cause health problems, but it can under certain process or storage conditions [141]. If the liquor collected and used for drinking is from the beginning or the end of the distillation process, when the temperatures are not ideal for making ethanol, it can be poisonous. Toxicants such as pesticides and heavy metals can come from contaminated containers used in either the distillation process (for example, car radiators) or storage. Another issue is the proof of the liquor. Higher proof liquor has less water in it. It can exacerbate already critical dehydration problems. A treatment intervention that is unlikely to work is to tell people not to drink lija. What may instead have positive results is education about how to make homemade alcohol safer for consumption, along with frequent hydration with clean water during consumption.

A feasible large-scale experiment that could help determine glyphosate's role in $\mathrm{CKDu}$ would be to compare cane cutters with no occupational exposure to glyphosate with cutters with occupational exposure to the herbicide. It would be necessary to monitor other risk factors in the experiment, matching the work conditions as closely as possible between the two groups. Organic sugarcane is grown in the Americas, with the most acreage in Paraguay, Argentina, Cuba, Columbia, Mexico, Ecuador, and the United States (data on Brazil is unavailable) $[142,143]$. Disease surveillance of sugarcane cutters at organic sugarcane plantations could be compared to cane cutters that work in fields where glyphosate is used.

\section{Conclusion}

$\mathrm{CKDu}$ is a global disease of increasing prevalence. $\mathrm{CKDu}$ has been identified in Nicaragua, El Salvador, Guatemala, Honduras, Costa Rica, Panama, Mexico, Egypt, Sri Lanka and India, with markedly fewer cases in Cuba, Dominican Republic and Brazil, possibly because of access to better medical care for workers [10,142,144,145]. However, in Brazil, the largest producer of sugarcane in the world, it has been postulated that CKDu is either underdiagnosed or undertreated [146]. A number of known risk factors appear to contribute to chronic kidney disease in Mesoamerican agricultural workers, but they do not explain the meteoric rise of kidney failures. Glyphosate exposure not only damages the kidneys directly, but also can be predicted to increase the damaging effects of multiple other factors, most significantly urate synthesis from fructose, exposure to mycotoxins and metal toxicity. The health crisis among sugarcane workers on the Pacific coast of Central America can be addressed in numerous ways, but the action most likely to prevent end-stage renal failure is to stop using glyphosate on sugarcane.

We would like to close with a quote from an editorial by Dr. Andrew Campbell, who summarizes well our own feelings on this subject: "No one should be surprised that this chemical compound, the world's number one herbicide, glyphosate, can be toxic. We regularly add chemicals to our ecosystem only to find out years or decades later that we should have been more diligent in making sure all the effects of these chemicals had been studied. This is the time for all of us to read again Rachel Carson's "The Silent Spring" [147,148]. 
Citation: Seneff S, Orlando LF (2018) Is Glyphosate a Key Factor in Mesoamerican Nephropathy? J Environ Anal Toxicol 7: 542. doi: 10.4172/21610525.1000542

\section{Acknowledgments}

This research is supported in part by Quanta Computers, Taiwan, under the auspices of the Qmulus program.

\section{References}

1. Kuwabara M, Hisatome I, Roncal-Jimenez CA, Niwa K, Andres-Hernando A, et al. (2017) Increased serum sodium and serum osmolarity are independent risk factors for developing chronic kidney disease; 5-year cohort study. PLoS One 12: e0169137.

2. Ordunez P, Martinez R, Reveiz L, Chapman E, Saenz C, et al. (2014) Chronic kidney disease epidemic in Central America: Urgent public health action is needed amid causal uncertainty. PLoS Neglected Tropical Diseases 8: e3019.

3. Mejía R, Quinteros E, López A, Ribó A, Cedillos H, et al. (2014) Pesticidehandling practices in agriculture in El Salvador: an example from 42 patient farmers with chronic kidney disease in the Bajo Lempa region. Occupational Diseases and Environmental Medicine 2: 56-70.

4. Wijkström J, Leiva R, Elinder CG, Leiva S, Trujillo Z, et al. (2013) Clinical and pathological characterization of Mesoamerican nephropathy: a new kidney disease in Central America. Am J Kidney Dis 62: 908-918.

5. Peraza S, Wesseling C, Aragon A, Leiva R, Garca-Trabanino RA, et al. (2012) Decreased kidney function among agricultural workers in El Salvador. Am J Kidney Dis 59: 531-540.

6. Jayasumana C, Gunatilake S, Senanayake P (2014) Glyphosate, hard water and nephrotoxic metals: Are they the culprits behind the epidemic of chronic kidney disease of unknown etiology in Sri Lanka? Int J Environ Res Public Health 11: 2125-2147.

7. Weaver VM, Fadrowski JJ, Jaar BG (2015) Global dimensions of chronic kidney disease of unknown etiology (CKDu): a modern era environmental and/ or occupational nephropathy? BMC Nephrol 16: 145.

8. Badria FA, Li S, Shier WT (1996) Fumonisins as potential causes of kidney disease. Journal of Toxicology: Toxin Reviews 15(3): 273-292.

9. VanDervort DR, López DL, Orantes CM, Rodríguez DS (2014) Spatial distribution of unspecified chronic kidney disease in El Salvador by crop area cultivated and ambient temperature. MEDICC Rev 16: 31-38.

10. Clark PA, Chowdhury J, Chan B, Radigan N (2016) Chronic kidney disease in Nicaraguan sugarcane workers: a historical, medical, environmental analysis and ethical analysis. The Internet Journal of Third World Medicine 12:1.

11. Herrera R, Orantes CM, Almaguer M, Alfonso P, Bayarre HD, et al. (2014) Clinical characteristics of chronic kidney disease of nontraditional causes in Salvadoran farming communities. MEDICC Review 16: 39-48.

12. Jayasinghe $S$ (2014) Chronic kidney disease of unknown etiology should be renamed chronic agrochemical nephropathy. MEDICC Review 16: 72-74.

13. Dalley CD, Richard EP Jr (2010) Herbicides as ripeners for sugarcane. Weed Science 58: 329-333.

14. Orgeron AJ, Petrie EC, Gravois KA (2017) Sugarcane response to glyphosate ripener when mixed with 2, 4-D or Atrazine. Journal of the American Society of Sugar Cane Technologists 37: 13-21.

15. Silva MA, Arantes MT, Oliver R, Brunelli MC (2014) Sugarcane tolerance to ratoon eradication with glyphosate determined by physiological responses. Planta Daninha 32: 207-214.

16. Jayasumana $C$, Paranagama $P$, Agampodi $S$, Wijewardane $C$, Gunatilake $S$ et al (2015) Drinking well water and occupational exposure to herbicides is associated with chronic kidney disease, in Padavi-Sripura, Sri Lanka. Environ Health 14: 6

17. Jayasumana C, Gunatilake S, Siribaddana S (2015) Simultaneous exposure to multiple heavy metals and glyphosate may contribute to Sri Lankan agricultural nephropathy. BMC Nephrol 16: 103.

18. Benbrook CM (2016) Trends in glyphosate herbicide use in the United States and globally. Environmental Sciences Europe 28: 3.

19. Rho YH, Zhu Y, Choi HK (2011) The epidemiology of uric acid and fructose. Semin Nephrol 31: 410-419.

20. Ruttens A, Blanpain AC, De Temmerman L, Waegeneers N (2012) Arsenic speciation in food in Belgium. Part 1: Fish, mollusks and crustaceans. J Geochem Explor 121: 55-61.
21. Navas-Acien A, Francesconi KA, Silbergeld EK, Guallar E (2011) Seafood intake and urine concentrations of total arsenic, dimethylarsinate and arsenobetaine in the US population. Environ Res 111: 110-118.

22. Sanoff SL, Callejas L, Alonso CD, Hu Y, Colindres RE, et al. (2010) Positive association of renal insufficiency with agriculture employment and unregulated alcohol consumption in Nicaragua. Ren Fail 32: 766-777.

23. Fon TAD, Uhing EH (1961) Stauffer Chemical Co. U.S. patent number 3160632 A, filed: January 30, 1961; awarded: December 8, 1964.

24. Cox CL, Stanhope KL, Schwarz JM, Graham JL, Hatcher B, et al. (2012) Consumption of fructose- but not glucose- sweetened beverages for 10 weeks increases circulating concentrations of uric acid, retinol binding protein-4, and gamma-glutamyl transferase activity in overweight/obese humans. Nutr Metab (Lond) 9: 68.

25. Johnson RJ, Segal MS, Srinivas TR, Ejaz A, Mu W, et al. (2005) Essential hypertension, progressive renal disease and uric acid: A pathogenetic link? J Am Soc Nephrol 16: 1909-1919.

26. Johnson RJ, Segal MS, Sautin Y, Nakagawa T, Feig DI, et al. (2007) Potential role of sugar (fructose) in the epidemic of hypertension, obesity and the metabolic syndrome, diabetes, kidney disease, and cardiovascular disease. Am J Clin Nutr 86: 899-906.

27. Cirillo P, Sautin YY, Kanellis J, Kang DH, Gesualdo L, et al. (2009) Systemic inflammation, metabolic syndrome and progressive renal disease. Nephrol Dial Transplant 24: 1384-1387.

28. Mayes PA (1993) Intermediary metabolism of fructose. Am J Clin Nutr 58:754S-765S

29. Emmerson BT (1974) Effect of oral fructose on urate production. Ann Rheum Dis 33: $276-280$

30. Gersch MS, Mu W, Cirillo P, Reungjui S, Zhang L, et al. (2007) Fructose but not dextrose accelerates the progression of chronic kidney disease. Am J Physio Renal Physiol 293: 1256-1261.

31. Roncal-Jimenez C, García-Trabanino R, Barregard L, Lanaspa MA, Wesseling $C$, et al. (2016) Heat stress nephropathy from exercise-induced uric acid crystalluria: a perspective on Mesoamerican nephropathy. Am J Kidney Dis 67 20-30.

32. Santos UP, Zanetta DMT, Terra-Filho M, Burdmann EA (2015) Burnt sugarcane harvesting is associated with acute renal dysfunction. Kidney International 87: 792-799.

33. Silveira HC, Schmidt-Carrijo M, Seidel EH, Scapulatempo-Neto C, LongattoFilho A, et al. (2013) Emissions generated by sugarcane burning promote genotoxicity in rural workers: a case study in Barretos, Brazil. Environ Health 12: 87.

34. García-Trabanino R, Jarquín E, Wesseling C, Johnson RJ, González-Quiroz $M$, et al. (2015) Heat stress, dehydration, and kidney function in sugarcane cutters in El Salvador-A cross-shift study of workers at risk of Mesoamerican nephropathy. Environ Res 142: 746-55.

35. Paula Santos U, Zanetta DM, Terra-Filho M, Burdmann EA (2015) Burnt sugarcane harvesting is associated with acute renal dysfunction. Kidney Int 87: 792-799.

36. Crowe J, van Wendel de Jode B, Wesseling C (2009) A pilot field evaluation on heat stress on sugarcane workers in Costa Rica: What to do next? Global Health Action 2: 2062.

37. Xu J, Li G, Wang Z, Si L, Sijie H, et al. (2016) The role of L-type amino acid transporters in the uptake of glyphosate across mammalian epithelial tissues. Chemosphere 145: 487-494.

38. Liu J, Martin JW (2017) Prolonged Exposure to Bisphenol A from Single Dermal Contact Events. Environmental Science \& Technology 51: 9940-9949.

39. Samsel A, Seneff S (2013) Glyphosate's Suppression of Cytochrome P450 Enzymes and Amino Acid Biosynthesis by the Gut Microbiome: Pathways to Modern Diseases. Entropy 15: 1416-1463.

40. Shehata AA, Schrödl W, Aldin AA, Hafez HM, Krüger M (2013) The effect of glyphosate on potential pathogens and beneficial members of poultry microbiota in vitro. Curr Microbiol 66: 350-358

41. Ramezani A, Massy ZA, Meijers B, Evenepoel P, Vanholder R, et al. (2016) Role of the Gut Microbiome in Uremia: A Potential Therapeutic Target. Am J Kidney Dis 67: 483-98. 
Citation: Seneff S, Orlando LF (2018) Is Glyphosate a Key Factor in Mesoamerican Nephropathy? J Environ Anal Toxicol 7: 542. doi: 10.4172/21610525.1000542

Page 8 of 10

42. Kim SC, Seo MY, Lee JY, Kim KT, Cho E, et al. (2016) Advanced chronic kidney disease: a strong risk factor for Clostridium difficile infection. Korean J Intern Med 31: 125-133.

43. Mutsaers HA, Caetano-Pinto $P$, Seegers AE, Dankers AC, van den Broek PH, et al. (2015) Proximal tubular efflux transporters involved in renal excretion of $\mathrm{p}$-cresyl sulfate and p-cresyl glucuronide: Implications for chronic kidney disease pathophysiology. Toxicol In Vitro 29: 1868-1877.

44. Kumeda Y, Asao T, Takahashi H, Ichinoe M (2003) High prevalence of B and $G$ aflatoxin-producing fungi in sugarcane field soil in Japan: Heteroduplex panel analysis identifies a new genotype within Aspergillus Section Flavi and Aspergillus nomius. FEMS Microbiol Ecol 45: 229-238.

45. Abdallah MF, Krska R, Sulyok M (2016) Mycotoxin Contamination in Sugarcane Grass and Juice: First Report on Detection of Multiple Mycotoxins and Exposure Assessment for Aflatoxins B1 and G1 in Humans. De Saeger S, Croubels S, Audenaert K, eds. Toxins 8: 343.

46. Gamalat A, Abd-Elaah GA, Samya Soliman A (2005) Occurrence of Fungal Species and Mycotoxins from Decayed Sugarcane (Saccharrum officinarum) in Egypt. Mycobiology 33: 77-83.

47. O'Brian E, Dietrich DR (2005) Ochratoxin A: the continuing enigma. Crit Rev Toxicol 35: 33-60.

48. Bennett JW, Klich M (2003) Mycotoxins. Clin. Microbiol. Rev 16: 497-516.

49. Pfohl-Leskowicz A, Manderville RA. Ochratoxin A (2007) An overview on toxicity and carcinogenicity in animals and humans. Mol Nutr Food Res 51: 61-99.

50. Peraica M, Radić B, Lucić A, Pavlović M (1999) Toxic effects of mycotoxins in humans. Bulletin of the World Health Organization 77: 754-766.

51. O'Brien, E, Dietrich DR (2005) Mycotoxins Affecting the Kidney. In: Tarloff JB, Lash LH (eds.): Toxicology of the kidney. 3rd edn., Boca Raton, Fla: CRC Press, pp: 895-936.

52. Takahashi $\mathrm{H}$, Kamimura $\mathrm{H}$, Ichinoe M (2004) Distribution of Aflatoxin-producing Aspergillus flavus and Aspergillus parasiticus in sugarcane fields in the Southernmost Islands of Japan. Journal of Food Protection 67: 90-95.

53. Boonen J, Malysheva SV, Taevernier L, Diana Di Mavungu J, De Saeger S, et al. (2012) Human skin penetration of selected model mycotoxins. Toxicology 301: 21-32.

54. Desalegn B, Nanayakkara S, Harada KH, Hitomi T, Chandrajith R, et al. (2011) Mycotoxin detection in urine samples from patients with chronic kidney disease of uncertain etiology in Sri Lanka. Bull Environ Contam Toxicol 87: 6-10.

55. Abid S, Hassen W, Achour A, Skhiri H, Maaroufi K, et al. (2003) Ochratoxin A and human chronic nephropathy in Tunisia: is the situation endemic? Hum Exp Toxicol 22: 77-84.

56. Ahmed AE, Alam-Eldin AOM (2015) An assessment of mechanical vs manual harvesting of the harvesting of the sugarcane in Sudan - The case of Sennar Sugar Factory. Journal of Saudi Sciences of Agricultural Sciences 14: 160-166.

57. Laws RL, Brooks DR, Amador JJ, Weiner DE, Kaufman JS, et al. (2015) Changes in kidney function among Nicaraguan sugarcane workers. Int J Occup Environ Health 21: 241-50.

58. Delgado CO (2009) Heat stress assessment among workers in a Nicaraguan sugarcane farm. Global Health Action 2:2069.

59. Johal GS, Huber DM (2009) Glyphosate effects on diseases of plants. Eur J Agron 31: 144-52.

60. Kremer RJ, Means NE (2009) Glyphosate and glyphosate-resistant crop interactions with rhizosphere microorganisms. European Journal of Agronomy 31: 153-61.

61. Nicolas V, Oestreicher N, Velot C (2016) Multiple effects of a commercial Roundup formulation on the soil filamentous fungus Aspergillus nidulans at low doses: evidence of an unexpected impact on energetic metabolism Agricultural soil ecosytems. Environ Sci Pollut Res 23: 14393-14404.

62. Barberis CL, Carranza CS, Chiacchiera SM, Magnoli CE (2013) Influence of herbicide glyphosate on growth and aflatoxin B1 production by Aspergillus section Flavi strains isolated from soil on in vitro assay, Journal of Environmental Science and Health, Part B: Pesticides, Food Contaminants, and Agricultural Wastes 48: 1070-1079.

63. Nicolas V, Oestreicher N, Velot C (2016) Multiple effects of a commercial Roundup formulation on the soil filamentous fungus Aspergillus nidulans at low doses: evidence of an unexpected impact on energetic metabolism Agricultural soil ecosytems. Environ Sci Pollut Res 23: 14393-14404.

64. Krzyśko-Łupicka T, Orlik A (1997) The use of glyphosate as the sole source of phosphorus or carbon for the selection of soil-borne fungal strains capable to degrade this herbicide. Chemosphere 34: 2601-2605.

65. Fernandez MR, Zentner RP, Basnyat P, Gehl D, Selles F, et al. (2009) Glyphosate associations with cereal diseases caused by Fusarium spp. in the Canadian Prairies European J Agon. 31: 133-143.

66. Schaaf GJ, Nijmeijer SM, Maas RFM, Roestenberg P, de Groene EM, et al (2002) The role of oxidative stress in the ochratoxin A-mediated toxicity in proximal tubular cells, Molecular Basis of Disease 1588: 149-158.

67. Minto RE, Townsend CA (1997) Enzymology and molecular biology of aflatoxin biosynthesis. Chem Rev 97: 2537-2555.

68. Zain ME (2011) Impact of mycotoxins on humans and animals. J Saudi Chem Soc 15: 129-144.

69. Abdel-Hamid AA, Firgany AEL (2015) Vitamin E supplementation ameliorates aflatoxin B-induced nephrotoxicity in rats, Acta Histochemica117: 767-779.

70. El-Mahalaway AM (2015) Protective effect of curcumin against experimentally induced aflatoxicosis on the renal cortex of adult male albino rats: a histological and immunohistochemical study. International Journal of Clinical and Experimental Pathology 8: 6019-6030.

71. Marin D, Taranu I (2002) Overview on aflatoxins and oxidative stress. Toxin Reviews 31: 32-43.

72. Liu S, Yao Y, Lu S, Aldous K, Ding X, et al. (2013) The role of renal proximal tubule P450 enzymes in chloroform-induced nephrotoxicity: utility of renal specific P450 reductase knockout mouse models. Toxicology and Applied Pharmacology 272: 230-237.

73. Richards IS (2008) Principles and Practice of Toxicology in Public Health. Jones and Bartlett Publishers.

74. de María N, Becerril JM, García-Plazaola JI. Hernandez A, De Felipe MR, et al (2006) New insights on glyphosate mode of action in nodular metabolism: Role of shikimate accumulation. J Agric Food Chem 54: 2621-2628.

75. Steinrücken HC, Amrhein N (1980) The herbicide glyphosate is a potent inhibitor of 5-enolpyruvylshikimic acid-3-phosphate synthase. Biochemical and Biophysical Research Communications 94: 1207-1212.

76. Vos MB, Lavine JE (2013) Dietary fructose in nonalcoholic fatty liver disease. Hepatology 57: 2525-31.

77. Mesnage R, Renney G, Séralini GE, Ward M, Antoniou MN (2017) Multiomics reveal non-alcoholic fatty liver disease in rats following chronic exposure to an ultra-low dose of Roundup herbicide. Sci Rep 7: 39328.

78. Swanson NL, Leu A, Abrahamson J, Wallet B (2014) Genetically engineered crops, glyphosate and the deterioration of health in the United States of America. J Organic Systems 9: 6-37.

79. Talbot AR, Shiaw MH, Huang JS, Yang SF, Goo TS, et al. (1991) Acute poisoning with a glyphosate-surfactant herbicide ('Roundup'): a review of 93 cases. Hum Exp Toxicol 10: 1-8.

80. Kim DK, Kim YH, Lee JH, Hwang SY, Cho KW, et al. (2015) The factors associated with the hypotension development in acute glyphosate-surfactant herbicide poisoning. J Korean Soc Emerg Med 26: 248-255.

81. Trojak B, Astruc K, Pinoit JM, Chauvet-Gelinier JC, Ponavoy E, et al. (2009) Hypokalemia is associated with lengthening of QT interval in psychiatric patients on admission. Psychiatry Res 169: 257-260.

82. Voiculescu M, lonescu C, Ismail G (2006) Frequency and prognostic significance of QT prolongation in chronic renal failure patients. Rom J Intern Med 44: 407-417.

83. Patanè S, Marte F, Di Bella G, Currò A, Coglitore S (2008) QT interva prolongation, torsade de pointes and renal disease. Int J Cardiol 13: e71-73.

84. Séralini GE, Clair E, Mesnage R, Gress S, Defarge N, et al. (2014) Republished study: long-term toxicity of a Roundup herbicide and a Roundup-tolerant genetically modified maize. Environ Sci Eur 26: 14.

85. Tizhe EV, Ibrahim NDG, Fatihu MY, Igbokwe IO, George BDJ, et al. (2013) Haematogical changes induced by subchronic glyphosate exposure: ameliorative effect of zinc in Wistar rats. Sokoto Journal of Veterinary Sciences. 11: 28-35. 
Citation: Seneff S, Orlando LF (2018) Is Glyphosate a Key Factor in Mesoamerican Nephropathy? J Environ Anal Toxicol 7: 542. doi: 10.4172/21610525.1000542

Page 9 of 10

86. Krüger M, Schrödl W, Neuhaus J, Shehata AA (2013) Field investigations of glyphosate in urine of Danish dairy cows. J Environ Anal Toxicol 3: 186.

87. Kupferman J, Amador JJ, Lynch KE, Laws RL, López-Pilarte D, et al. (2016) Characterization of Mesoamerican nephropathy in a kidney failure hotspot in Nicaragua. Am J Kidney Dis 68: 716-725.

88. de Liz Oliveira Cavalli VL, Cattani D, Heinz Rieg CE, Pierozan P, Zanatta L, et al. (2013) Roundup disrupts male reproductive functions by triggering calciummediated cell death in rat testis and Sertoli cells. Free Radic Biol Med 65: 335346.

89. Kašuba V, Milić M, Rozgaj R, Kopjar N, Mladinić M, et al. (2017) Effects of low doses of glyphosate on DNA damage, cell proliferation and oxidative stress in the HepG2 cell line. Environ Sci Pollut Res Int 24: 19267-19281.

90. Paz-y-Miño C, Sánchez ME, Arévalo M, Muñoz MJ, Witte T, et al. (2007) Evaluation of DNA damage in an Ecuadorian population exposed to glyphosate. Genetics and Molecular Biology 30: 456-460.

91. Mesnage R, Arno M, Costanzo M, Malatesta M, Séralini GE, et al. (2015) Transcriptome profile analysis reflects rat liver and kidney damage following chronic ultra-low dose Roundup exposure. Environmental Health 14: 70.

92. Knezevich A, Hogan GA (1983) Chronic Feeding Study of Glyphosate (Roundup Technical) in Mice: Project No. 77-2061: BDN-77420. Final Report. 1983.

93. Menè P, Punzo G (2008) Uric acid: bystander or culprit in hypertension and progressive renal disease? J Hypertens 26: 2085-2092.

94. Borghi C, Rosei EA, Bardin T, Dawson J, Dominiczak A, et al. (2015) Serum uric acid and the risk of cardiovascular and renal disease. J Hypertens 33 : 1729-1741.

95. Kim Y, Shin S, Kim K, Choi S, Lee K (2015) Effect of Urate Lowering Therapy on Renal Disease Progression in Hyperuricemic Patients with Chronic Kidney Disease. J Rheumatol 42: 2143-2148.

96. Avram Z, Krishnan E (2008) Hyperuricaemia - where nephrology meets rheumatology. Rheumatology (Oxford) 47: 960-964.

97. Iseki K, Ikemiya Y, Inoue T, Iseki C, Kinjo K, et al. (2004) Significance of hyperuricemia as a risk factor for developing ESRD in a screened cohort. Am J Kidney Dis 44: 642-650.

98. Edwards NL (2008) The role of hyperuricemia and gout in kidney and cardiovascular disease. Cleve Clin J Med 75 Suppl 5: S13-S16.

99. Kanbay M, Yilmaz MI, Sonmez A, Solak Y, Saglam M, et al. (2012) Serum uric acid independently predicts cardiovascular events in advanced nephropathy. Am J Nephrol 36: 324-331.

100. Ejaz AA, Mu W, Kang DH, Roncal C, Sautin YY, et al. (2007) Could uric acid have a role in acute renal failure? Clin J Am Soc Nephrol 2: 16-21.

101. Mazzali M, Hughes J, Kim YG, Jefferson JA, Kang D-H, et al. (2001) Elevated uric acid increases blood pressure in the rat by a novel crystal-independent mechanism. Hypertension 38: 1101-1106.

102. Epstein FH, Brezis M, Silva P, Rosen S (1987) Physiological and clinical implications of medullary hypoxia. Artif Organs 11: 463-467.

103. Gong $R$ (2012) The renaissance of corticotropin therapy in proteinuric nephropathies. Nat Rev Nephrol 8: 122-128.

104. Bomback AS, Radhakrishnan J (2011) Treatment of nephrotic syndrome with adrenocorticotropic hormone (ACTH). Discov Med 12: 91-96.

105.Si J, Ge Y, Zhuang S, Wang LJ, Chen S, et al. (2013) Adrenocorticotropic hormone ameliorates acute kidney injury by steroidogenic-dependent and -independent mechanisms. Kidney Int 83: 635-646.

106. Pandey A, Rudraiah M (2015) Analysis of endocrine disruption effect of Roundup in adrenal gland of male rats. Toxicology Reports 2: 1075-1085.

107. Cericato L, Neto JGM, Fagundes M, Kreutz LC, Quevedo RM, et al. (2008) Cortisol response to acute stress in jundiá Rhamdia quelen acutely exposed to sublethal concentrations of agrichemicals. Comp Biochem Physiol C 148 : 281-286.

108. Cericato L, Neto JG, Kreutz LC, Quevedo RM, da Rosa JG, et al. (2009) Responsiveness of the interrenal tissue of jundiá (Rhamdia quelen) to an in vivo ACTH test following acute exposure to sublethal concen- trations of agrichemicals. Comp Biochem Physiol C Toxicol Pharmacol 149: 363-407.

109.Laws RL, Brooks DR, Amador JJ, Weiner DE, Kaufman JS, et al. (2016)
Biomarkers of kidney injury among Nicaraguan sugarcane workers. Am J Kidney Dis 67: 209-217.

110. Barraclough KA, Blashki GA, Holt SG, Agar JWM (2017) Climate change and kidney disease threats and opportunities. Kidney International 92: 526-530.

111. Glaser J, Lemery J, Rajagopalan B, Diaz HF, Garca-Trabanino R, et al. (2016) Climate change and the emergent epidemic of CKD from heat stress in rura communities: The case for heat stress nephropathy. CJASN 11: 1472-1483.

112. Johnson R, Stenvinkel P, Jensen T, Lanaspa M, Roncal C, et al. (2016) Metabolic and kidney diseases in the setting of climate change, water shortage, and survival factors. Journal of the American Society of Nephrology 27: 2247-2256.

113. https://apps.fas.usda.gov/psdonline/circulars/Sugar.pdf

114. https://gain.fas.usda.gov/Recent\%20GAIN\%20Publications/12-2016.pdf

115. Tomei J (2015) The sustainability of sugarcane-ethanol systems in Guatemala: Land, labour and law. Biomass and Bioenergy 82: 94-100.

116. Martinelli LA, Filoso S (2008) Expansion of sugarcane ethanolproduction in Brazil: Environmental and social challenges. Ecological Applications 18: 885898.

117. Goldemberg J, Coelho ST, Guardabassi P (2008) The sustainability of ethanol production from sugarcane. Energy Policy 36: 2086-2097.

118. Elinder CG, Wernerson A, Wijkström J (2015) Mesoamerican Nephropathy $(\mathrm{MeN})$ : A new chronic kidney disease related to occupational heat exposure with repeated deprivation of salts and water. Int J Nephrol Kidney Failure Volume 1.

119.http://www.paho.org/hq/index.php? option =com\%20 content\&view=article\&id=9402

120.https://www.icij.org/project/island-widows/map-kidney-disease-deathscentral-america-2009.

121. International Consortium of Investigative Journalists. Project Methodology: Island of the Widows.

122. Ramirez-Rubio O (2013) Epidemic of chronic kidney disease of unknown causes causal hypotheses, and public health interventions.

123. Martín-Cleary C, Ortiz A (2014) CKD hotspots around the world: where, why and what the lessons are. A CKJ review series. Clinical Kidney Journal 7: 519-523.

124. Gifford FJ, Gifford R, Eddleston M, Dhaun N (2016) Endemic nephropathy across the world. Kidney Int Rep 2: 282-292.

125. Rodriguez-Iturbe B, Johnson RR, Herrera-Acosta J (2005) Tubulointerstitia damage and progression of renal failure. Kidney International 68: S82-S86.

126. Nanayakkara S, Komiya T, Ratnatunga N, Senevirathna ST, Harada KH, et al. (2012) Tubulointerstitial damage as the major pathological lesion in endemic chronic kidney disease among farmers in North Central Province of Sri Lanka. Environmental Health and Preventive Medicine 17: 213-221.

127. Correa-Rotter R, Wesseling C, Johnson RJ (2014) CKD of Unknown Origin in Central America: The case for a Mesoamerican Nephropathy. Am J Kidney Dis 63: $506-520$.

128. Berger K, Moeller MJ (2014) Mechanisms of epithelial repair and regeneration after acute kidney injury, Seminars in Nephrology 34: 394-403.

129. Huaizhen C, Busse LW (2017) Novel therapies for acute kidney injury. Kidney International Reports 2: 785-799.

130.Zidan RA, Elnegris HM, Wahdan RA (2015) Evaluating the protective role of ginseng against histological and biochemical changes induced by aflatoxin $\mathrm{B} 1$ in the renal convoluted tubules of adult male albino rats. J Clin Exp Patho 5: 253.

131. Jiménez-Osorio AS, García-Niño WR, González-Reyes S, Álvarez-Mejía AE, Guerra-León S, et al. (2016) The effect of dietary supplementation with curcumin on redox status and Nrf2 activation in patients with nondiabetic or diabetic proteinuric chronic kidney disease: A pilot study. J Ren Nutr 26: 237-244.

132. The National Kidney Foundation. https://www.kidney.org/atoz/content/ herbalsupp

133. Ucero A, Sabban B, Benito-Martin A, Ortiz A (2013) Laser therapy in metabolic syndrome-related kidney injury. Photochem Photobiol 89: 953-960. 
Citation: Seneff S, Orlando LF (2018) Is Glyphosate a Key Factor in Mesoamerican Nephropathy? J Environ Anal Toxicol 7: 542. doi: 10.4172/21610525.1000542

134. Oliveira FA, Moraes AC, Paiva AP, Schinzel V, Correa-Costa M, et al. (2012) Low-level laser therapy decreases renal interstitial fibrosis. Photomedicine and Laser Surgery 30: 705-713.

135. Koultcavenia EV (1998) Influence of LLLT on kidney functions. Proc SPIE 3569: $70-74$.

136. National Institutes of Health. https://clinicaltrials.gov/ct2/show/NCT02944760

137. Lunyera J, Mohottige D, von Isenburg M (2015) CKD of uncertain etiology: A systematic review. Clin J Am Soc Nephrol 11: 379-385.

138. Herrera Valdés R, Orantes CM, Almaguer López M, López Marín L, Arévalo PA, et al. (2015) Clinical characteristics of chronic kidney disease of nontraditional causes in women of agricultural communities in El Salvador. Clinical Nephrology 83: 56-63.

139. Cirillo P, Gersch MS, Mu W, Scherer PM, Kim KM, et al. (2009) Ketohexokinasedependent metabolism of fructose induces proinflammatory mediators in proximal tubular cells. J Am Soc Nephrol 20: 545-553.

140. Choi M (2009) Not-so-sweet side of fructose. J Am Soc Nephrol 20: 457-459.
141.Lachenmeier DW, Rehm J, Gmel G (2007) Surrogate alcohol: What do we know and where do we go? Alcoholism: Clinical and Experimental Research 31: 1613-1624.

142. Garibay SV, Ugas R. Organic Farming in Latin America and the Caribbean http://orgprints.org/17931/1/garibay-ugas-2009-world-organic-agriculture.pdf

143. ASR Group. https://www.asr-group.com/about-us/our-owners

144. Almaguer M, Herrera R, Orantes CM (2014) Chronic kidney disease of unknown etiology in agricultural communities. MEDICC Review 16: 9-15.

145.Laux TS, Barnoya J, Guerrero DR, Rothstein M (2015) Dialysis enrollment patterns in Guatemala: evidence of the chronic kidney disease of nontraditional causes epidemic in Mesoamerica. BMC Nephrology 16: 54.

146. Oliveira MB, Romão JE Jr, Zatz R (2005) End-stage renal disease in Brazil: epidemiology, prevention, and treatment. Kidney Int Suppl 97: S82-S86.

147. Carson R (1962) Silent Spring. Houghton Mifflin, Boston MA.

148. Campbell AW (2014) Glyphosate: Its effects on humans. Alternative Therapies 20: 9-10. 